\title{
Plasmid profiles and restriction enzyme fragmentation patterns of plasmids of methicillin-sensitive and methicillin-resistant isolates of Staphylococcus aureus from hospital and the community.
}

\author{
J.E. COIA, I. NOOR-HUSSAIN and D.J.PLATT
}

\section{University Department of Bacteriology, Glasgow Royal Infirmary, Cast/e Street, Glasgow G4 OSF}

\begin{abstract}
Summary. The number, frequency distribution and restriction enzyme fragmentation patterns of plasmids harboured by 163 methicillin-sensitive isolates of Staphylococcus aureus (MSSA) and 53 methicillin-resistant isolates (MRSA) were compared. Plasmids were demonstrated in less than half of the MSSA isolates; their frequency distribution did not differ from that predicted by a simple model of plasmid distributions. In contrast, all the MRSA isolates harboured plasmids, their distribution suggesting dissemination of a limited number of clones within the hospital. Among 72 MSSA isolates harbouring plasmids, 38 different restriction patterns were identified. There were fewer patterns among MRSA isolates; 11 were observed, and two predominant patterns accounted for $68 \%$ of those identified. These restriction patterns correlated with the presence or absence of aminoglycoside resistance. A multicopy plasmid of $2.6 \mathrm{~kb}$ was present in both MSSA and MRSA isolates that harboured more than one plasmid; it had the same restriction pattern irrespective of its source. The importance of these results in choosing a method of studying the spread of staphylococci is discussed.
\end{abstract}

\section{Introduction}

Staphylococcus aureus is a major human pathogen that produces a wide spectrum of disease ranging from superficial skin lesions to severe systemic infections (Shanson, 1986). Widespread outbreaks of nosocomial infection caused by methicillinresistant isolates have renewed interest in this species.

Methicillin-resistant $S$. aureus (MRSA) were first reported in the early 1960 s shortly after the introduction of methicillin into clinical practice, and by the late 1960 s constituted a small but significant proportion of all $S$. aureus isolates. Their incidence declined in the early 1970s (Jepsen, 1986), but in the last decade there has been a resurgence of MRSA isolates often resistant to many antibiotics. Since the early 1980 s significant outbreaks due to such isolates have been reported from Australia, North America, South Africa, Greece, the Middle East and much of Europe, including the United Kingdom (Casewell, 1986). In Glasgow Royal

Received 28 Jan. 1988; accepted 3 June 1988.
Infirmary, MRSA at present account for $3-5 \%$ of all isolates of $S$. aureus (D. R. Baird, personal communication).

The genetic basis of antibiotic resistance in staphylococci has long been a subject of interest and speculation amongst microbiologists (Lacey, 1972, 1975; Shalita et al., 1980), and new techniques in molecular biology, e.g., restriction enzyme fragmentation patterns, nucleic acid hybridisation and molecular cloning, have recently been applied to study it. Individual plasmids mediating resistance in MRSA isolates have been studied by Townsend et al. (1984, 1985a, 1985b), and the plasmids carried by resistant isolates by Dowd et al. (1983) and Kayser et al. (1986). However, a clearer understanding of the ecology of staphylococcal plasmids in strains causing disease requires first that the relative abundance and distribution of plasmids within defined collections of bacteria is determined (Platt et al., 1984, 1986a).

In this study, the plasmid profiles and plasmid DNA restriction enzyme fragmentation patterns of a collection of MRSA isolates and of methicillinsensitive isolates representative of those in the 
hospital and the community have been examined and compared.

\section{Materials and methods}

\section{Bacterial strains}

A series of 216 isolates of $S$. aureus was studied, comprising (from Glasgow Royal Infirmary): 53 MRSA isolates; 50 consecutive methicillin-sensitive isolates (MSSA) from blood cultures (BC); 63 MSSA isolates from other routine diagnostic specimens (RD); and 50 MSSA isolates from the noses of patients attending a general practitioner's surgery (GP). All were identified as $S$. aureus on the basis of their colony morphology and positive results in coagulase and latex agglutination (Staphaurex, Wellcome) tests. Multiple isolates from the same patient were excluded. Three isolates of epidemic MRSA (EMRSA) from London, two from St Bartholomew's Hospital and one from St Thomas's Hospital were also examined.

\section{Antibiotic sensitivity testing}

Sensitivity to methicillin, streptomycin, kanamycin, gentamicin, vancomycin, trimethoprim, mupirocin, penicillin, erythromycin, clindamycin, fucidin, tetracycline, chloramphenicol and teicoplanin was determined by disk-diffusion tests in which the radii of inhibition zones were compared with critical radii $\left(\mathrm{R}_{\mathrm{c}}\right)$ previously determined for a fully sensitive strain of $S$. aureus (strain GRI 22686). The sizes of critical radii were calculated from $R_{c}=\bar{x}-3 \sigma$, where $\bar{x}$ was the mean radius obtained from 12 determinations and $\sigma$ was the standard deviation. If an antibiotic produced an inhibition zone less than $R_{c}$, the isolate was deemed to be resistant to it (Platt et al., $1986 a$ ).

\section{Determination of plasmid profiles}

About $25 \%$ of the growth from overnight cultures on nutrient agar at $37^{\circ} \mathrm{C}$ was washed in $500 \mu \mathrm{l}$ of a solution containing $50 \mathrm{~mm}$ tris, $50 \mathrm{mM} \mathrm{NaCl}$ and $5 \mathrm{~mm}$ disodium EDTA, pH 8.0 (TES), and suspended in $400 \mu$ l of TES containing $50 \mathrm{~mm}$ sucrose to which $50 \mu \mathrm{l}$ of a solution of lysostaphin $(1 \mathrm{mg} / \mathrm{ml})$ and $50 \mu \mathrm{l}$ of a solution of lysozyme $(40 \mathrm{mg} / \mathrm{ml})$ were added. After incubation for $10 \mathrm{~min}$ at $37^{\circ} \mathrm{C}, 400 \mu \mathrm{l}$ of a solution of sodium dodecyl sulphate, $10 \% \mathrm{w} / \mathrm{v}$ (SDS) was added to complete lysis. The lysates were centrifuged for $15 \mathrm{~min}$ at $12000 \mathrm{rpm}$, and the plasmids in the supernate were separated by electrophoresis in an agarose gel $(0.7 \% \mathrm{w} / \mathrm{v})$ as described by Platt and Sommerville (1981) and Platt et al. (1984). The molecular sizes of the plasmids were estimated by comparison with standard plasmids of known size. The size of small plasmids was estimated by comparing their mobility with that of a set of low-mol. wt standard supercoiled plasmids (Supercoiled Ladder, Gibco-BRL, Paisley), as described by Platt and Taggart (1987).

\section{Preparation of purified plasmid DNA and restriction enzyme fragmentation}

Cultures incubated overnight in $10 \mathrm{ml}$ of brain heart infusion broth (BHI) were centrifuged at $4000 \mathrm{rpm}$ for $5 \mathrm{~min}$, the cell pellet was washed in TES buffer, resuspended in $200 \mu \mathrm{l}$ of TES containing $50 \mathrm{~mm}$ sucrose, treated with lysozyme and lysostaphin as described above and the cells then lysed with alkaline SDS. Plasmid DNA was extracted, purified and digested with restriction enzymes following the sequence described by Platt $e t$ al . (1986b); the enzymes used were PstI, HaeIII and AluI (Gibco-BRL). In addition, the enzymes AvaII, HindIII, SmaI, EcoRI, Bsp 1286 and AluI were employed in attempts to cleave low-mol. wt plasmids present in some of the isolates. The size of restriction fragments was estimated from a standard curve produced by fitting a robust modified hyperbola to the observed mobilities of fragments of known mol. wt of bacteriophage $\lambda$ digested by the enzyme PstI (Plikaytis et al., 1986).

\section{Statistical analysis}

The prevalence of plasmids in the different collections of strains was compared by means of the $\mathrm{X}^{2}$-squared test (Siegel, 1956). Plasmid distributions were compared with values predicted from mathematical models based on the Poisson and modified Poisson curves as previously described by Platt (1987). The relatedness of plasmids was determined by calculation of their coefficients of similarity, $\left(S_{D}\right)($ Dice, 1945).

\section{Results}

\section{Resistance to antibiotics}

The percentage of isolates in each group resistant to none, one, two or three or more of the antibiotics tested is shown in table 1 . Penicillin resistance accounted for most of the resistance of MSSA isolates whereas, as expected, all the MRSA isolates were resistant to three or more antibiotics and could be further divided into two equal groups on the basis of their sensitivity to aminoglycosides. One of the aminoglycoside-sensitive MRSA isolates was mupirocin resistant (Baird and Coia, 1987).

\section{Plasmid profiles}

Plasmids were detected in $42 \%$ of the $\mathrm{BC}$ isolates, $48 \%$ of the GP isolates and $41 \%$ of the RD isolates. All the MRSA isolates harboured plasmids. The frequency distributions of plasmids in the BC, GP and RD groups did not differ significantly ( $p>$ 0.5 ). When the $\mathrm{BC}, \mathrm{GP}$ and $\mathrm{RD}$ isolates were combined to form a methicillin-sensitive group their plasmid distribution differed significantly 
Table I. Distribution of resistance determinants in isolates from different sources

\begin{tabular}{c|rrrr}
\hline & \multicolumn{4}{|c}{$\begin{array}{l}\text { Percentage of isolates resistant to } \\
\text { the given number of antibiotics }\end{array}$} \\
\cline { 2 - 5 } $\begin{array}{c}\text { Number of resistance } \\
\text { determinants/isolate }\end{array}$ & BC & GP & RD & MRSA \\
\hline 0 & 6 & 32 & 11 & 0 \\
1 & 78 & 54 & 53 & 0 \\
2 & 10 & 10 & 24 & 0 \\
3 & 6 & 4 & 12 & 100 \\
\hline
\end{tabular}

$\mathrm{BC}=$ blood cultures; $\mathrm{GP}=$ general practitioners $\mathrm{RD}=$ routine diagnostic; MRSA = methicillin-resistant $S$. aureus.

( $p<0.001$ ) from that of the MRSA isolates (table II).

Almost all of the plasmids identified were either $14-51 \mathrm{~kb}$ or $2.9-5.8 \mathrm{~kb}$ in size. In isolates with a single plasmid, it was always of the larger size, but when there was more than one plasmid both sizes were invariably present. Typical plasmid profiles are shown in fig. 1 .

\section{Restriction enzyme fragmentation patterns}

Among the plasmids from 125 isolates, 49 different restriction patterns were found. Eleven representative patterns resulting from digestion with HaeIII are shown in fig. 2; in all cases the HaeIII restriction patterns correlated well with those obtained by digestion with Pst I and AluI. Eleven patterns were identified among the plasmids from the MRSA isolates; these fell into two groups, and correlated with the presence or absence of

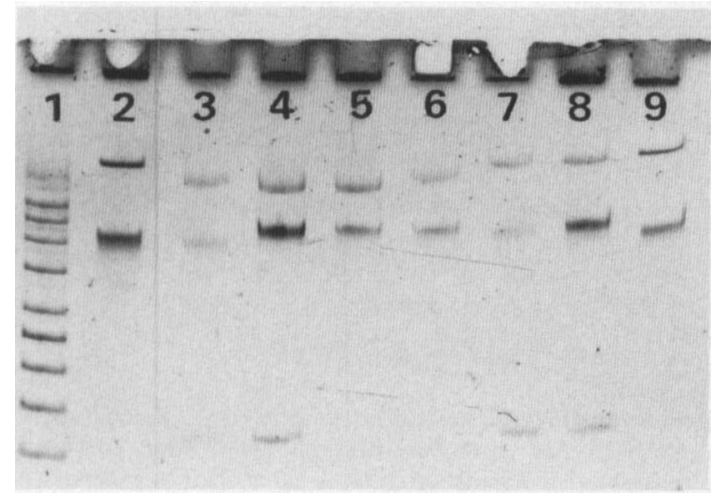

Fig. 1. Typical $S$. aureus plasmid profiles. Lane $1-$ Supercoiled ladder standards; lanes 2 and 9-52 kb plasmid standards; lanes 3, 4, 5 and 6-MSSA; lane 7-aminoglycoside-sensitive MRSA; lane 8-aminoglycoside-resistant MRSA.
Collection

Number of plasmids Number of strains
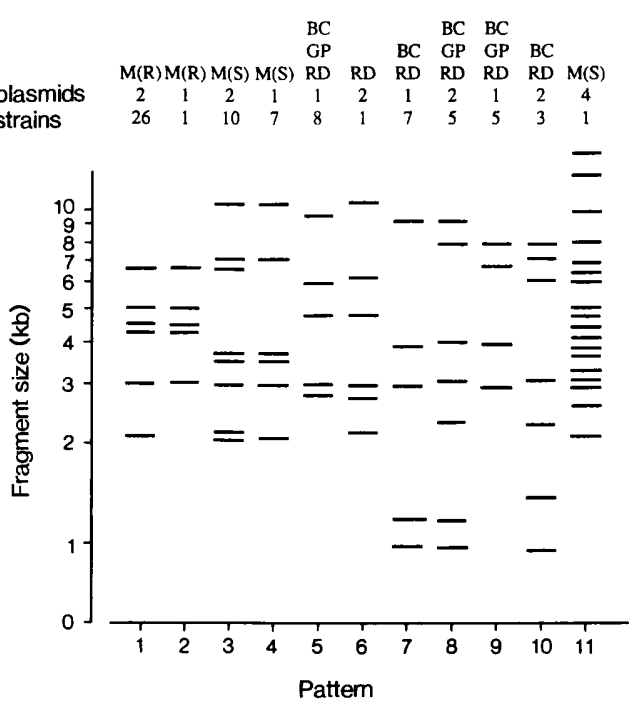

Fig. 2. Examples of HaeIII restriction patterns of $S$. aureus together with the sources of strains, the number of plasmids harboured, and number of strains showing identical fingerprints. $\mathbf{M}(\mathrm{R})$ and $\mathbf{M}(\mathrm{S})$ represent aminoglycoside-resistant and sensitive isolates respectively.

aminoglycoside resistance. The patterns from the plasmids of 26 of the 28 aminoglycoside-resistant isolates were identical (pattern 1, fig. 2), and the $S_{D}$ values of the remainder were $>80 \%$. The 25 patterns from plasmids from the aminoglycosidesensitive isolates varied more: 11 were identical (pattern 3, fig. 2), and the $S_{D}$ values of a further seven were $>80 \%$ (pattern 4 , fig. 2). The remainder of the aminoglycoside-sensitive MRSA isolates shared a number of fragments with the predominant pattern $\left(\mathrm{S}_{\mathrm{D}}>40 \%\right)$, and the single isolate which carried four plasmids and was also the mupirocinresistant isolate (pattern 11, fig. 2), shared fragments with both the major patterns from plasmids of MRSA isolates.

The patterns from plasmids from MSSA isolates were much more heterogeneous and, although six patterns accounted for more than $40 \%$ of the strains (patterns 5, 6, 7, 8, 9, and 10, fig. 2), 38 different patterns were identified. None of the patterns from MRSA isolates was present amongst those from MSSA isolates although some restriction fragments were common to both; e.g., a fragment of $2.7 \mathrm{~kb}$ after digestion with HaeIII was present in all the digest patterns from the MRSA isolates and in the patterns from more than $70 \%$ of the MSSA isolates. Particularly noteworthy were small, multicopy plasmids present in those MRSA and MSSA isolates that harboured two plasmids. These were not cleaved by PstI, HaeIII, AvaII, HindIII, SmaI, 
Table II. Frequency distribution of plasmids in isolates from different sources

\begin{tabular}{c|ccccc}
\hline & \multicolumn{4}{|c}{ Number (\%) of isolates with the given number of plasmids } \\
\cline { 2 - 6 } $\begin{array}{c}\text { Number of } \\
\text { plasmids isolate }\end{array}$ & $\begin{array}{c}\text { BC } \\
(\mathrm{n}=50)\end{array}$ & $\begin{array}{c}\text { GP } \\
(\mathrm{n}=50)\end{array}$ & $\begin{array}{c}\text { RD } \\
(\mathrm{n}=63)\end{array}$ & $\begin{array}{c}\text { All MSSA } \\
(\mathrm{n}=163)\end{array}$ & $\begin{array}{c}\text { MRSA } \\
(\mathrm{n}=53)\end{array}$ \\
\hline 0 & $29(58)$ & $26(52)$ & $37(59)$ & $92(56)$ & 0 \\
1 & $19(38)$ & $22(44)$ & $22(35)$ & $63(39)$ & $6(11)$ \\
2 & $2(4)$ & $2(4)$ & $4(6)$ & $8(5)$ & $44(83)$ \\
3 & 0 & 0 & 0 & 0 & $2(4)$ \\
4 & 0 & 0 & 0 & 0 & $1(2)$ \\
\hline
\end{tabular}

EcoRI or Bsp1286 enzymes as was shown by their comparative mobility in profile and digest gels, and by evidence of open circle and dimer formation. However, digestion with $A l u I$ enzyme produced five fragments, the total molecular size of which $(2.6 \mathrm{~kb})$ agreed well with estimates from profile gels, and confirmed the homogeneity of this small plasmid. The observed differences between patterns 1 and 2 , between 3 and 4 , between 5 and 6 , and between 7 and 8 reflect the presence or absence of this plasmid. Restriction fragmentation patterns that demonstrate some of the above features, including examples of those from plasmids of EMRSA isolates are shown in fig. 3.

Considering together the mol. wts of the fragments obtained by digestion and the plasmid profiles, it appears that the aminoglycoside-resistant MRSA isolates carried a highly conserved plasmid of $18 \mathrm{~kb}$, whereas more than $70 \%$ of the aminoglycoside-sensitive MRSA isolates carried a plasmid of $23 \mathrm{~kb}$. The rest of the aminoglycosidesensitive MRSA isolates harboured a variety of plasmids with sizes in the range $17-26 \mathrm{~kb}$, but which on the basis of restriction patterns were less closely related, either to each other or to the other plasmids in MRSA isolates. The plasmids of MSSA isolates were more heterogeneous; more than 30 different plasmids with sizes in the range 14-51 kb were identified. Those MRSA and MSSA isolates that carried more than one plasmid harboured a small plasmid of $2.6 \mathrm{~kb}$. These plasmids were indistinguishable regardless of their origin. The commonest plasmids from the MSSA isolates, as judged by restriction patterns, were present in both hospital and community isolates.

\section{Discussion}

The results of this study show that the plasmids of isolates of MSSA and MRSA differ in their prevalence, number, distribution, and restriction patterns. Although plasmid-free MRSA have been described by Gelmi et al. (1987), all the MRSA isolates examined in this study carried plasmids, in sharp contrast to the MSSA isolates of which more than half were plasmid-free. The frequency distribution of the plasmids in each group (table II) also differed markedly. Among MSSA isolates, the observed frequency distribution of plasmids did

\section{2}

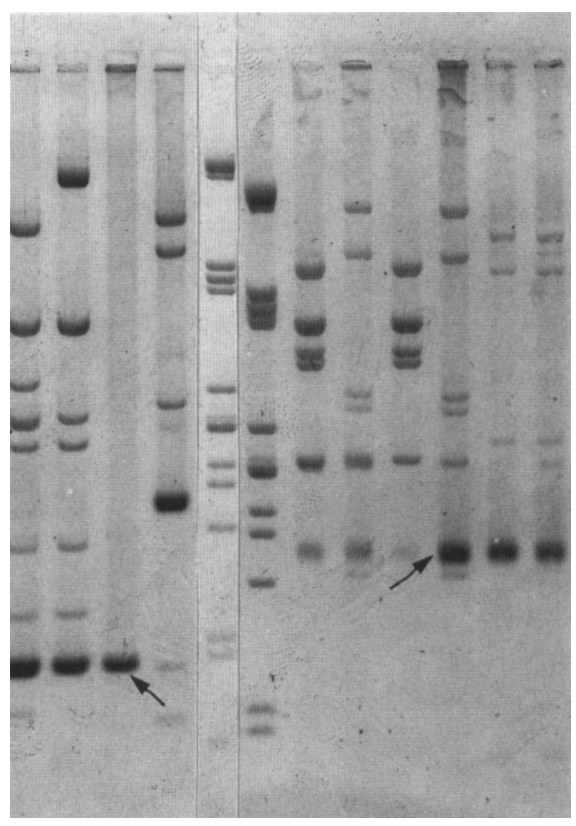

Fig. 3. Typical HaeIII restriction patterns of $S$. aureus. Lanes 15 and 6-12 are from two different gels; lanes 5 and 6bacteriophage $\lambda /$ PstI fragments as calibration standards from each gel; lanes 1-3-EMRSA; lanes 7 and 9-aminoglycosideresistant MRSA; lanes 8 and 10-aminoglycoside-sensitive MRSA; lanes 4, 11 and 12-MSSA. Arrows indicate small multicopy plasmids present in MRSA and MSSA and their larger size with respect to those found in EMRSA. 
Table III. Comparison of observed plasmid distributions in MSSA and MRSA with distributions predicted by a modified Poisson model

\begin{tabular}{c|ccccc}
\hline & \multicolumn{3}{c}{ Number of isolates with the given number of plasmids } \\
\cline { 2 - 3 } $\begin{array}{c}\text { Number of } \\
\text { plasmids/isolate }\end{array}$ & \multicolumn{2}{|c}{ MSSA } & & \multicolumn{2}{c}{ MRSA } \\
\cline { 2 - 3 } \cline { 5 - 6 } & observed & predicted & & observed & predicted \\
\hline 1 & 62 & 63 & & 6 & 25 \\
2 & 10 & 8 & & 44 & 17 \\
3 & 0 & 0 & & 2 & 8 \\
4 & 0 & 0 & 1 & 3 \\
\hline
\end{tabular}

not differ from that predicted by the modified Poisson model developed to analyse the distribution of plasmids among representative collections of enterobacteria (Platt, 1987). This suggests, firstly, that the substantial proportion of plasmid-free MSSA isolates are poor plasmid recipients and, secondly, that accumulation of plasmids by gramnegative and gram-positive genera may be subject to the same variables. By contrast, the frequency distributions of plasmids from MRSA isolates differed significantly $(\mathrm{p}<0.001)$ from that predicted by the model (table III), and were consistent with the hypothesis that the MRSA isolates represent dissemination of a limited number of clones within the hospital.

This view is supported by the limited number of restriction patterns among the plasmids carried by MRSA isolates, in marked contrast to the diversity of patterns among the plasmids from the MSSA isolates. Although this suggests an exogenous source of the MRSA with their subsequent spread consequent upon selection pressure, the findings with respect to small multicopy plasmids can be interpreted as support for the evolution of MRSA de novo from indigenous hospital strains. The small number of MSSA strains collected that harboured two plasmids does not preclude the existence of MRSA progenitors amongst MSSA in the hospital. It is interesting that amongst the MSSA isolates the commonest larger plasmids were present in both hospital and community isolates. It is likely that

\section{REFERENCES}

Baird D, Coia J E 1987 Mupirocin-resistant Staphylococcus aureus. Lancet 2: 387-388.

Casewell M W 1986 Epidemiology and control of the 'modern' methicillin-resistant Staphylococcus aureus. Journal of Hospital Infection 7 Suppl A : 1-11. this reflects interchange of strains, although it may represent exchange of plasmids.

Many of the strains of MRSA isolated from patients in different hospitals in England and which have been described as epidemic MRSA (EMRSA) (Cookson et al., 1986) carry small plasmids similar in size to those of local MRSA as described here. However, their restriction patterns (fig. 3) differ markedly from those of local MRSA. The small plasmids harboured by MRSA and MSSA from this hospital are similar but differ from the plasmids of EMRSA; this suggests evolution de novo of local MRSA from local methicillin-sensitive strains. However, MSSA strains harbouring two plasmids are rare; if MRSA strains have evolved from them, the plasmids have played at best an indirect role in such evolution as methicillin resistance is not plasmid-mediated.

The diversity of restriction patterns found amongst strains with apparently similar plasmid profiles, particularly MSSA, suggest that, if such patterns are stable, increased strain discrimination is possible with this technique. Clearly, this has important implications for the value of such analysis in studying the spread of strains in the community.

We thank Professor Morag Timbury for her encouragement, Dr B. Keighley (Balfron Health Centre, Balfron) for his assistance in collecting community isolates, and Professor Soad Tabaqchali and Dr B. Cookson for providing the EMRSA isolates. We gratefully acknowledge the financial support of the Scottish Hospitals Endowment Research Trust for this work.
Cookson B, Talsania H, Naidoo J, Phillips I 1986 Strategies for typing and properties of epidemic methicillin-resistant Staphylococcus aureus. European Journal of Clinical Microbiology 5: 702-709.

Dice L R 1945 Measures of the amount of ecologic association between species. Ecology $26: 297-302$.

Dowd G, Cafferkey M, Dougan G 1983 Gentamicin- and 
methicillin-resistant Staphylococcus aureus in Dublin hospitals; molecular studies. Journal of Medical Microbiology 16: 129-138.

Gelmi M, Foresti I, Ravizzola G, Bonfanti C, Verardi R, Caruso A, Turano A 1987 Antibiotic resistances and plasmids in Staphylococcus aureus from Italian hospitals. Journal of Medical Microbiology 23: 111-118.

Jepsen O B 1986 The demise of the 'old' methicillin-resistant Staphylococcus aureus. Journal of Hospital Infection 7 Suppl A: 13-17.

Kayser F H, Berger-Bachi B, Beck W D 1986 Genetics of multiply-resistant Staphylococcus aureus. Journal of Hospital Infection 7 Suppl A: 19-27.

Lacey R W 1972 Genetic control in methicillin-resistant strains of Staphylococcus aureus. Journal of Medical Microbiology 5 : 497-508.

Lacey R W 1975 Antibiotic resistance plasmids of Staphylococcus aureus and their clinical importance. Bacteriological Reviews 39: 1-32.

Platt D J, Sommerville J S 1981 Serratia species isolated from patients in a general hospital. Journal of Hospital Infection 2: 341-348.

Platt D J, Sommerville J S, Kraft C A, Timbury M C 1984 Antimicrobial resistance and the ecology of Escherichia coli plasmids. Journal of Hygiene 93: 181-188.

Platt D J, Brown D J, Munro D S 1986a. The distribution of plasmids among a representative collection of Scottish strains of salmonellae. Journal of Hygiene 97 : 199-204.

Platt D J, Chesham J S, Brown D J, Kraft C A, Taggart J $1986 b$ Restriction enzyme fingerprinting of enterobacterial plas- mids: a simple strategy with wide application. Journal of Hygiene 97 : 205-210.

Platt D J, Taggart J 1987 Molecular epidemiology: determination of plasmid sizes. Focus 9: 3-13.

Platt D J 1987 A simple statistical approach that represents the frequency distribution of plasmids in clinical isolates of the enterobacteria. Journal of Medical Microbiology 23: 255260.

Plikaytis B D, Carlone G M, Edmonds P, Mayer L W 1986 Robust estimation of standard curves for protein molecular weight and linear-duplex DNA base-pair number after gel electrophoresis. Analytical Biochemistry 152: 346-364.

Shanson D C 1986 Staphylococcal infections in hospital. British Journal of Hospital Medicine 35: 312-320.

Shalita Z, Murphy E, Novick R P 1980 Penicillinase plasmids of Staphylococcus aureus: structural and evolutionary relationships. Plasmid 3: 291-311.

Siegel S 1956 Non parametric statistics for the behavioural sciences. McGraw-Hill, London, pp 104-111.

Townsend D E, Ashdown N, Greed L C, Grubb W B 1984 Analysis of plasmids mediating gentamicin resistance in methicillin-resistant Staphylococcus aureus. Journal of Antimicrobial Chemotherapy 13: 347-352.

Townsend D E, Ashdown N, Momoh M, Grubb W B $1985 a$. Distribution of plasmid-borne resistance to nucleic acid binding compounds in methicillin-resistant Staphylococcus aureus. Journal of Antimicrobial Chemotherapy 15 : 417-434.

Townsend D E, Bolton S, Ashdown N, Grubb W B $1985 b$ Transfer of plasmid-borne aminoglycoside resistance determinants in staphylococci. Journal of Medical Microbiology 20: $169-185$. 